\title{
Antimicrobial Sensitivity of Neonatal Bacterial Sepsis
}

\author{
Nadya Iswandari, ${ }^{1}$ Aris Primadi, ${ }^{2}$ Sunarjati Sudigdoadi ${ }^{3}$ \\ ${ }^{1}$ Faculty of Medicine Universitas Padjadjaran, ${ }^{2}$ Department of Child Health Faculty of Medicine \\ Universitas Padjadjaran/Dr. Hasan Sadikin General Hospital Bandung, ${ }^{3}$ Department of \\ Microbiology and Parasitology Faculty of Medicine Universitas Padjadjaran
}

\begin{abstract}
Background: Appropriate treatment on neonatal bacterial sepsis is important based on the exact etiology to prevent bacterial resistance, but bacterial identification using blood cultures requires a considerable time. The newest data of various bacteria and their sensitivity can be used to assist empirical antibiotics usage. This study was conducted to identify bacterial profile that caused neonatal sepsis and their sensitivity to antibiotics at Dr. Hasan Sadikin General Hospital Bandung..

Methods: A total of 275 neonatal sepsis cases and 288 blood cultures results were collected from a database provided by Dr. Hasan Sadikin General Hospital Bandung during the period of July 2011 toDecember 2012 (three semesters). Etiology of the bacteria and antimicrobial sensitivity profile data were taken from positive bacteria results. Then, these variables were processed using the descriptive method and classified by semester

Result: The most common bacteria that caused neonatal sepsis in the second semester 2011 is Serratia marescens, the first semester 2012 was Enterobacter aerogenes and in the second semester 2012 was Burkholderia cepacia. The most sensitive antibiotics were piperacillin tazobactam, cefepime, meropenem and amikacin in all three semesters, gentamycin in the second semester 2011 and 2012, and amoxicillin clavulanic in the second semester 2012.
\end{abstract}

Conclusions: Bacterial and antimicrobial sensitivity profile is varied in every semester.

Keywords: Antimicrobial sensitivity profile, bacterial profile, neonatal sepsis

\section{Introduction}

Most of neonatal deaths in Indonesia are caused by sepsis. ${ }^{1}$ Treatment of neonatal sepsis is prescribed based on the bacterial profile sensitivity to antimicrobial. However, both bacterial and sensitivity profile tend to be varied at different times and in different places. In Indonesia, a study conducted at Dr. Cipto Mangunksumo Hospital in 2008, revealed that Acinetobacter calcoaceticus, Staphylococcus epidermidis, Enterobacter aerogenes and Pseudomonas sp., were the most common bacteria in neonatal sepsis. ${ }^{2}$ In developing countries, the most frequent etiologies for neonatal sepsis were Staphylococcus aureus, Escherichia coli and Klebsiella sp. ${ }^{3}$ In developed countries, early onset neonatal sepsis is mostly caused by group B Streptococcus. ${ }^{4}$

An appropriate treatment is important based on the exact etiology, but bacterial identification using blood cultures requires a considerable time. On the other hand, the usage of broad spectrum antibiotics could increase risk of loss of bacterial sensitivity to antibiotics given, resulting in bacterial resistance. ${ }^{5}$

To solve this situation, the newest data of bacteria that commonly caused neonatal sepsis was needed to assist empirical antibiotics usage. At Dr. Hasan Sadikin General Hospital, bacterial profile is routinely studied in the Department of Clinical Pathology every semester. Yet, bacterial and antimicrobial sensitivity profile in infants born at Dr. Hasan Sadikin General Hospital were scarce. Moreover, decision in using a certain antibiotic depends on the variety of antibiotics provided by the government health insurance Uaminan Persalinan/Jampersal) such as ampicillin, gentamycin, and cefotaxime.

This study was conducted to identify the bacterial and sensitivity profile to antibiotics

Correspondence: Nadya Iswandari, Faculty of Medicine, Universitas Padjadjaran, Jalan Raya Bandung-Sumedang Km.21, Jatinangor, Sumedang, Indonesia, Phone: +62 81280282436 Email: nadiswandari@gmail.com 
that cause neonatal sepsis at Dr. Hasan Sadikin General Hospital.

\section{Methods}

Data base of all neonatal sepsis patients were collected from the second semester of 2011 and two semesters of 2012 at Dr. Hasan Sadikin General Hospital Bandung.

The inclusion criteria in this study was neonatal sepsis patients. Incomplete data and non-bacterial neonatal sepsis were excluded in this study. Then a total of 275 neonatal sepsis cases and 288 blood cultures results were identified. The incompatibility of the number of samples between the patients and the blood cultures occurred because one patient might have his/her blood culture examined more than once.

The variables in this study were bacterial and sensitivity profile data. Then, the data was processed using the descriptive method and the results were classified in semester to describe the pattern of culture results, bacterial profile in frequency and antimicrobial sensitivity in percentage. This study was approved by the Health Research Ethics Committee at Dr. Hasan Sadikin General Hospital Bandung.

\section{Results}

From the total of 288 blood cultures in three semesters, the distribution of the presence of bacteria was slightly higher than the distribution of sterile specimen in their blood cultures (Table 1).

The most common bacteria that causes neonatal sepsis was varied. In the second semester of 2011 were Serratia marescens, Klebsiella pneumoniae and Staphylococcus haemolyticus, in the first semester of 2012 the most common bacteria that caused neonatal sepsis were Enterobacter aerogenes, Staphylococcus haemolyticus, and Klebsiella pneumoniae. In the second semester of 2012 were Burkholderia cepacia, Staphylococcus haemolyticus and Enterobacter cloacae.
The most sensitive antibiotics in the second semester of 2011 were piperacillin tazobactam, cefepime, meropenem, amikacin and gentamycin. In the first semester of 2012 were piperacillin tazobactam, cefepime, meropenem and amikacin. In the second semester of 2012 were piperacillin tazobactam, amoxicillin clavulanic, cefepime, amikacin and gentamycin.

\section{Discussion}

Culture results revealed positive results were slightly higher than sterile results. These results were similar to a study conducted at Dr. Cipto Mangunkusumo Hospital. ${ }^{2}$ In routine clinical practice, negative culture results are almost inevitable in many cases caused by inadequate blood sample volume. ${ }^{6}$

In this study, bacteria that were considered as contaminant bacteria such as Coagulase negative staphylococci, Corynebacterium, Bacillus and Micrococcus are excluded from results. ${ }^{7}$ Based on the results, there was causative diversity in neonatal sepsis cases. In the second semester of 2011 bacteria that mostly caused neonatal sepsis are Serratia marcescens, Klebsiella pneumoniae, Staphylococcus haemolyticus and Staphylococcus aureus. A similar study in Yale ${ }^{8}$ also concluded that the causative pathogen of neonatal sepsis continue to change. Serratia marcescens is normal flora in gastrointestinal tract and opportunis pathogen. It commonly caused infection in hospital setting especially patients with venous catheter. ${ }^{9}$ In the first semester of 2012 bacteria that mostly caused neonatal sepsis are Enterobacter aerogenes, Staphylococcus haemolyticus and Klebsiella pneumoniae whereas Serratia marcescens only 2 cases occurred in this period. Enterobacter aerogenes is a free living bacteria and normal flora in gastrointestinal tract. ${ }^{9}$ In the second semester of 2012 bacteria that mostly caused neonatal sepsis are Burkholderia cepacia, Staphylococcus haemolyticus and Enterobacter cloacae whereas Enterobacter aerogenes was not found in this period. Burholderia

Table 1 Culture Results of Neonatal Sepsis Patients

\begin{tabular}{lccc}
\hline & Second Semester & First Semester & Second Semester \\
& $\mathbf{2 0 1 1}$ & $\mathbf{2 0 1 2}$ & $\mathbf{2 0 1 2}$ \\
\cline { 2 - 4 } & $\mathbf{n}$ & $\mathbf{n}$ & $\mathbf{n}$ \\
\hline Bacteria & 30 & 45 & 53 \\
Steril & 34 & 51 & 51 \\
\hline
\end{tabular}


cepacia is commonly found in water and environment. In hospital setting this bacteria transmit between patients, and often infect infants. ${ }^{9}$ This result proved bacterial profile that caused neonatal sepsis was varied. Based on literature, Staphylococcus can be acquired from primary sepsis or nosocomial. Klebsiella and Serratia commonly caused nosocomial sepsis. ${ }^{10}$ Enterobacter is an Enterobactericeae family, similar as Escherichia coli which is primary sepsis etiology. However, Klebsiella pneumoniae and Serratia marcescens were one of the most common bacterial cause of early onset neonatal sepsis, so nosocomial infection was unlikely. Staphylococcus haemolyticus was the most frequent bacterial cause of early onset neonatal sepsis, then based on literature those cases were primary sepsis. ${ }^{10}$ In asimilar study conducted in Dr. Cipto Mangunkusumo Hospital $^{2}$, another state hospital, there was a significant difference between causative bacteria in neonatal sepsis. The most common bacteria that caused neonatal sepsis in Dr. Cipto Mangunkusumo hospital are Acinetobacter calcoaceticus, followed by Enterobacter aerogenes, Pseudomonas, Escherichia coli and Klebsiella pneumoniae. Except Enterobacter aerogenes and Klebsiella pneumoniae, these bacteria also caused neonatal sepsis in Dr. Hasan Sadikin General Hospital, but in much lower cases. In other developing country, the most bacteria caused neonatal sepsis are Staphylococcus aureus, Escherichia coli, and Klebsiella. ${ }^{3}$ Except for Escherichia coli, these bacteria also caused neonatal sepsis in Dr. Hasan Sadikin General hospital in high number. A study conducted in India ${ }^{11}$ also reveal causative bacteria variability at different times. Furthermore, Klebsiella pneumoniae and Enterobacter aerogenes found decreased in incidence and Staphylococcus aureus increased in incidence. In this study Klebsiella pneumoniae and Enterobacter aerogenes were found in high number. In developed countries, the most bacteria caused neonatal sepsis are Group B Streptococci. In Dr. Hasan Sadikin General Hospital, there were no Group B Streptococci positive culture results found. ${ }^{12}$

In this study the most sensitive antibiotics in the second semester of 2011 were piperacillin tazobactam, cefepime, meropenem, amikacin and gentamycin, in the first semester of 2012 were piperacillin tazobactam, cefepime, meropenem and amikacin, in the second semester of 2012 were piperacillin tazobactam, amoxicillin-clav, cefepime, amikacin and gentamycin. Cefotaxime and ceftazidime also had high sensitivity percentage in the second semester of 2011 and 2012. This result was similar to a study conducted in Dr. Cipto Mangunkusumo Hospital2 ${ }^{2}$, which reported meropenem has high sensitivity level. This was different with literature that suggest to use ampicillin to treat early onset neonatal sepsis. ${ }^{10}$ Ampicillin was only tested in 4 cases and only $25 \%$ had sensitivity level. Ampicillin and gentamicin was preferably recommended in developed countries but not in Dr. Hasan Sadikin General Hospital, due to causative bacteria difference as described above. ${ }^{12}$ In nosocomial sepsis, literature suggest to use vancomycin, and based on result vancomycin has high sensivitity level but only tested in 36 cases. ${ }^{10}$ Antibiotics that used for gram negative bacteria, in this study amikacin and gentamicin, has lower sensitivity level than meropenem. Antibiotics is used for gram positive bacteria, in this study linezolid and vancomycin, had high sensitivity level, but gram positive bacteria cases were much lower than gram negative bacteria cases, then broad spectrum antibiotics, meropenem, cefepime, piperacillin, ceftazidime and cefotaxime gave more gram positive and negative bacteria coverage. On the one hand, amikacin also had high sensitivity level. Apart from sensitivity level, the antibiotic selection also had to consider the price of antibiotics itself.

Most of Dr. Hasan Sadikin General Hospital patients were insured by Jampersal coverage. Antibiotics available for this insurance were ampicillin, gentamycin and cefotaxime. Ampicilin has low sensitivity level as described above, and gentamycin also has lower sensitivity than other aminoglycoside antibiotic, amikacin. Cefotaxime, still has high sensitivity level. On the other hand, another study found that concurrent use of cefotaxime during the first 3 days after birth associated with an increased risk of death, compared with the concurrent use of gentamycin. ${ }^{13}$ In addition, this study could be an evidence based study to recommend other sensitive antibiotics to be borne by government in upcoming Jaminan Kesehatan Nasional programme, and included in formularium.

Limitation of this study was lack of data between January-June 2011. This study needs periodic study to describe etiology and antimicrobial sensitivity profile due its variability.

\section{References}

1. Departemen Kesehatan Republik Indonesia. Ibu selamat, bayi sehat, suami 
siaga. 2010. [cited 13 February 2013]; Available from: http://www.depkes.go.id/ index.php/berita/press-release/790-ibuselamat-bayi-sehat-suami-siaga.html.

2. Juniatiningsih A, Aminullah A, Firmansyah A. Profil mikroorganisme penyebab sepsis neonatorum di Departemen Ilmu Kesehatan Anak Rumah Sakit Cipto Mangunkusumo Jakarta. Sari Pediatri. 2008;10(1):60-5.

3. Waters D, Jawad I, Ahmad A, Luksic I, Nair $\mathrm{H}$, Zgaga L, et al. Aetiology of communityacquired neonatal sepsis in low and middle income countries. J Glob Health. 2011;1(2):154-70.

4. Stoll BJ, Hansen NI, Sánchez PJ, Faix RG, Poindexter BB, Van Meurs KP, et al. Early onset neonatal sepsis: The burden of Group B Streptococcal and E. coli disease continues. Pediatrics. 2011;127(5):817-26.

5. Tenover FC. Mechanisms of antimicrobial resistance in bacteria. Am J Infect Control. 2006;34(5 Suppl 1):S3-10;discussion S64-73.

6. Connell TG, Rele M, Cowley D, Buttery JP, Curtis N. How reliable is a negative blood culture result? Volume of blood submitted for culture in routine practice in a children's hospital. Pediatrics. 2007;119(5):891-6.

7. Hall KK, Lyman JA. Updated review of blood culture contamination. Clin Microbiol Rev. 2006;19(4):788-802.

8. Bizzarro MJ, Raskind C, Baltimore RS, Gallagher PG. Seventy-five years of neonatal sepsis at Yale: 1928-2003. Pediatrics. 2005;116(3):595-602.

9. Brooks G, Carroll KC, Butel J, Morse S. Jawetz, Melnick, \& Adelberg's medical microbiology, 25th ed: New York: McGrawHill Companies, Incorporated; 2007.

10. Sundaram V, Kumar P, Dutta S, Mukhopadhyay K, Ray P, Gautam V, et al. Blood culture confirmed bacterial sepsis in neonates in a North Indian tertiary care center: changes over the last decade. Jpn J Infect Dis. 2009;62(1):46-50.

11. Polin RA. Management of neonates with suspected or proven early-onset bacterial sepsis. Pediatrics. 2012: 129(5): 1006-15.

12. Clark RH, Bloom BT, Spitzer AR, Gerstmann DR. Empiric use of ampicillin and cefotaxime, compared with ampicillin and gentamicin, for neonates at risk for sepsis is associated with an increased risk of neonatal death. Pediatrics. 2006;117(1): 67-74. 